\title{
Communications
}

\section{Growth Mechanism of $\gamma$-MnS Nanorod-Arrays by Hydrothermal Method on Anodic Aluminum Oxide Template}

\author{
Jianming Huang, ${ }^{\dagger}$ Weifeng Liu, ${ }^{\dagger,+, *}$ Yong Lv, ${ }^{\dagger}$ and Lianzeng Yao ${ }^{\dagger, \dagger}$ \\ ${ }^{\dagger}$ CAS Key Laboratory of Materials for Energy Conversion, Chinese Academy of Science, Hefei, Anhui 230026, P. R. China \\ ${ }^{\ddagger}$ Department of Materials Science and Engineering, University of Science and Technology of China, Hefei, \\ Anhui 230026, P. R. China. "E-mail: liuwf@ustc.edu.cn \\ Received October 8, 2009, Accepted June 21, 2010
}

Key Words: Nanorod-arrays, MnS, Anodic aluminum oxide

$\mathrm{MnS}$, as a p-type semiconductor with a wide gap $\left(\mathrm{E}_{\mathrm{g}}=3.7\right.$ $\mathrm{eV}$, has a potential application in solar cell as a window/buffer, but also is linked with the study of diluted magnetic semiconductor (DMS). . So far, a number of methods have been developed to fabricate different nanostructure $\mathrm{MnS}$ such as solvothermal method for preparing hierarchical architectures $\mathrm{MnS},{ }^{2}$ biomolecule-assisted method for synthesizing porous MnS networks, ${ }^{3}$ and chemical bath deposition method for making crystalline $\mathrm{MnS}$ thin film. ${ }^{4}$ Hydrothermal method is a general, low-cost and convenience method which was utilized for synthesis of nanomaterials. ${ }^{5-7}$ Our research group has reported that oriented $\mathrm{MnS}$ nanorods on anodic aluminum oxide template were synthesized under a hydrothermal condition and demonstrated the effect of precursor content on the morphology evolution of assamples. ${ }^{8}$ In order to research the growth mechanism of the arrays, herein we synthesized $\mathrm{MnS}$ nanorod arrays by combination of anodic aluminum oxide template and hydrothermal method on different substrates.

Through-hole anodic aluminum oxide templates were prepared using $\mathrm{Al}$ foil $(99.999 \%$ ) via a two-step anodization process as described in literature. ${ }^{8}$ To investigate the effect of different substrates on the morphology of the-products, different substrates including anodic aluminum oxide template (sample A), one-step anodization $\mathrm{Al}$ foil (sample $\mathrm{B}$, which was prepared by first anodizing $\mathrm{Al}$ foil for $10 \mathrm{~h}$ and then removing the alumina layer with the mixed acid $\left(0.6 \mathrm{M} \mathrm{H}_{3} \mathrm{PO}_{4}\right.$ and $\left.0.15 \mathrm{M} \mathrm{H}_{2} \mathrm{CrO}_{4}\right)$, where the foil still kept the close-packed concave nano-pits consistently with the nanopole of anodic aluminum oxide template), $\mathrm{Al}$ foil (sample $\mathrm{C}$, dipped in $\mathrm{HNO}_{3}$ solution and covered by a compact alumina layer), Si wafer (sample D) respectively were put into Teflon-lined stainless steel autoclaves of $20 \mathrm{~mL}$ capacity filled with $16 \mathrm{~mL}$ mixed solution consisting of $2 \mathrm{~mol} / \mathrm{L}$ $\mathrm{MnCl}_{4}$ and $2 \mathrm{~mol} / \mathrm{L}$ thiourea. We kept the reaction at $150{ }^{\circ} \mathrm{C}$ for $20 \mathrm{~h}$. When reactions completed the products were washed three times with distilled water and absolute ethanol, respectively. Then the products were dried in an oven at $60{ }^{\circ} \mathrm{C}$.

The powder XRD patterns (not showed here) reveal that the as-prepared products on different substrates were $\gamma$-MnS with lattice constants of $\mathrm{a}=3.979 \AA$ and $\mathrm{c}=6.447 \AA$ (JCPDS, No. 40-1289). And Figure 1 shows the typical SEM images of anodic aluminum oxide template and the as-prepared products on different substrates. b) - e) are respectively corresponding to on sample $\mathrm{A} \sim \mathrm{D}$. Figure 1a reveals that the anodic aluminum oxide template has highly ordered pores with a diameter of about $60 \mathrm{~nm}$. The similar grass-like, packed nanorod arrays could be seen in a large range from Figure 1b and Figure 1c, which was obviously different from the products on other substrates that hold similar bulk-particle morphology showed in Figure $1 \mathrm{~d}$ and $1 \mathrm{e}$. The nanorods arrays have a diameter of about $50 \sim 70 \mathrm{~nm}$ and a length of about $600 \mathrm{~nm}$. Because the surface of sample A and B preserved the similarly close-packed nanostructure surface, and the sample C and D have the same smoothly surface although the sample $\mathrm{C}$ has the same components with sample $\mathrm{A}$ and $\mathrm{B}$, it was reasonable that the nano-structure
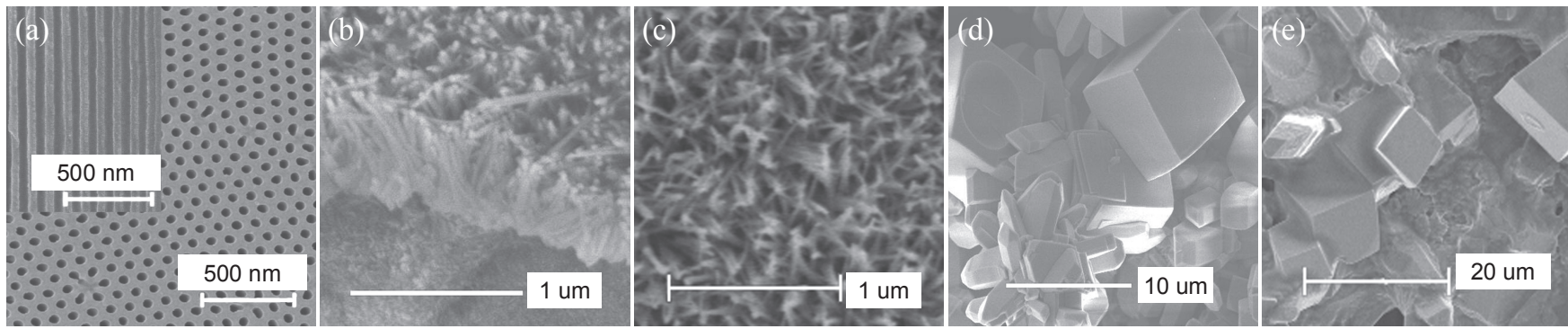

Figure 1. (a) SEM image of anodic aluminum oxide template, inset cross-section image of anodic aluminum oxide template (b)-(e) SEM images of the products on different substrates respectively corresponding to anodic aluminum oxide template, one-step anodization $\mathrm{Al}$ foil, $\mathrm{Al}$ foil (dipped in $\mathrm{HNO}_{3}$ solution) and silicon wafer. 


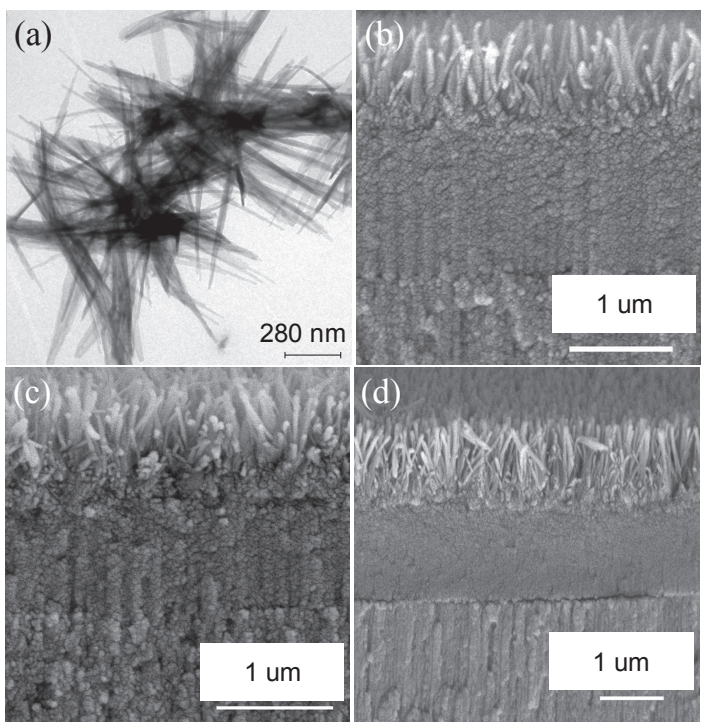

Figure 2. (a) TEM image of the sample prepared at $150{ }^{\circ} \mathrm{C}$ for $20 \mathrm{~h}$, and SEM images of the samples prepared at $150{ }^{\circ} \mathrm{C}$ on anodic aluminum oxide templates respectively for (b) $10 \mathrm{~h}$, (c) $20 \mathrm{~h}$ and (d) $30 \mathrm{~h}$.

surface of the substrate may be the key role which lead to the form of nanorod arrays morphology, but the nanorod arrays were formed on a buffer layer, instead of directly on the substrate, which has rarely reported.

The TEM image of the sample prepared on anodic aluminum oxide template at $150^{\circ} \mathrm{C}$ for $20 \mathrm{~h}$ was shown in Figure 2a. The nanorods have a taper-shape, with a length range from $500 \mathrm{~nm}$ to $600 \mathrm{~nm}$, which is consistent with the results showed in Figure $1 \mathrm{~b}$ and $1 \mathrm{c}$. The EDS map (not showed here) revealed that the manganese content was far more than the sulfur content, not in 1:1 ratio. We inferred that it was possible that the most of sulfur was depleted by the $\mathrm{Cu}$ grid because we observed the morphology of $\mathrm{Cu}$ grid changed during TEM imaging process.

Figure 2b-d shows the typical cross-section SEM images of the as-prepared products on anodic aluminum oxide templates with different reaction duration $(10 \mathrm{~h}, 20 \mathrm{~h}$ and $30 \mathrm{~h})$ at $150{ }^{\circ} \mathrm{C}$. From the SEM images, we can observe that nearly all the samples on anodic aluminum oxide templates for different reaction time hold the similar morphology character and consisted of two layers, transition layer at the bottom and grass-like nanorodarrays layer on the top, and the thickness of transition layer almost keep at a constant about $1 \mu \mathrm{m}$. A number of mechanism were utilized to explain morphology evolution including Nucleation-Dissolution-Recrystallization, ${ }^{9}$ Secondary Nucleation and Growth, ${ }^{10}$ Oriented Attachment, ${ }^{11}$ Ostwald Ripening ${ }^{12}$ and Strain-Relaxation induction, ${ }^{13}$ namely utilizing lattice-match or lattice-mismatch principles to synthesizing kinds of nanoscale materials. And we also suggested that the nanopores of anodic aluminum oxide template may play an important role in controlling the local concentration which leads to an inhomogeneous concentration distribution and may affect the shape development. ${ }^{14-16}$ But, as Figure $2 b-d$ revealed, a transition layer has been clearly found and no changed with extending duration time, which was inconsistent with our foregone suggestion.

The formation of 1D structure is a highly kinetic-driven reaction. Supersaturation in the growth region is favorable to an anisotropic growth as the shape of a crystal is determined by the relative specific surface energy of each facet of the crystal. Therefore, the initial deposition of nanocrystals is critical for the formation of the aligned nanorods. Here we propose our view on the morphology revolution mechanism. Firstly the chemical reaction mechanism described as following: at $150{ }^{\circ} \mathrm{C}$ thiourea decomposed into $\mathrm{H}_{2} \mathrm{~S}$ which dissociated into $\mathrm{S}^{2-}$ ion in solution and then $\mathrm{S}^{2-}$ ion combining with $\mathrm{Mn}^{2+}$ formed $\mathrm{MnS}$ precipitation.

Then the morphology revolution mechanism is as follows: at the beginning, a MnS wetting layer was firstly formed on anodic aluminum oxide template surface under the supersaturation conduction, and the wetting layer still hold the order-arrays character (showed in Figure 2b, 2c and 2d), which possible induced by the close-packed nanopore arrays of anodic aluminum oxide template. When the thickness of wetting layer reached a critical value, which was still unknown, the nanorod arrays would form on the wetting layer. The critical thickness of wetting layer may be determined by the reaction system energy, or by MnS supersaturation which decreased along the duration. We have done other experments to further validating our view, for example we can produce a MnS seeds film on glass substrate by CBD (chemical bath deposition) and then dipped the substrate in $16 \mathrm{~mL}$ mixed solution consisting of $2 \mathrm{~mol} / \mathrm{L}$ $\mathrm{MnCl}_{4}$ and $2 \mathrm{~mol} / \mathrm{L}$ thiourea at $150{ }^{\circ} \mathrm{C}$ for $20 \mathrm{~h}$ to examine whether forming nanorod or nanowire arrays. But no nanorods array was formed on the substrate, which implied that, the close-packed nanostructure of the substrate play a key role on the formation of $\mathrm{MnS}$ nanorod arrays.

\section{References and Notes}

1. Brieler, F. J.; Grundmann, P.; Froba, M.; Chen, L. M.; Klar, P. J.; Heimbrodt, W.; von Nidda, H. A. K.; Kurz, T.; Loidl, A. Eur. J. Inorg. Chem. 2005, 3597.

2. Cheng, Y.; Wang, Y. S.; Jia, C.; Bao, F. J. Phys. Chem. B 2006, $110,24399$.

3. Zuo, F.; Zhang, B.; Tang, X. Z.; Xie, Y. Nanotechnology 2007, $18,215608$.

4. Gumus, C.; Ulutas, C.; Esen, R.; Ozkendir, O. M.; Ufuktepe, Y. Thin Solid Films 2005, 492, 1.

5. Piao, Y. Z.; Lim, H.; Chang, J. Y.; Lee, W. Y.; Kim, H. Electrochimica Acta 2005, 50, 2997.

6. Gasparac, R.; Kohli, P.; Mota, M. O.; Trofin, L.; Martin, C. R. Nano. Letters 2004, 4, 513.

7. Zhao, L. L.; Steinhart, M.; Gosele, U.; Schlecht, S. Adv. Mater. 2008, 20, 1218.

8. Zhang, C.; Tao, F.; Liu, G. Q.; Yao, L. Z.; Cai, W. L. Materials Letters 2008, 62, 246.

9. Masuda, H.; Fukuda, K. Science 1995, $268,1466$.

10. Yan, L.; Yu, R. B.; Chen, J.; Xing, X. R. Crystal Growth \& Design 2008, 8, 1474.

11. Sounart, T. L.; Liu, J.; Voigt, J. A.; Huo, M.; Spoerke, E. D.; McKenzie, B. J. Am. Chem. Soc. 2007, 129, 15786.

12. Cheng, Y.; Wang, Y. S.; Chen, D. Q.; Bao, F. J. Phys. Chem. B 2005, 109, 794.

13. Yang, H. G.; Zeng, H. C. J. Phys. Chem. B 2004, 108, 3492.

14. Li, Y. R.; Liang, Z.; Zhang, Y.; Zhu, J.; Jiang, S. W.; Wei, X. H. Thin Solid Films 2005, 489, 245.

15. Gibert, M.; Puig, T.; Obradors, X. Surface Science 2007, 601, 2680.

16. Wang, Y. D.; Zang, K. Y.; Chua, S. J. Appl. Phys. Lett. 2006, 89, 263116. 